\title{
Fracture Resistance of Nd:YAG Laser-welded Cast Titanium Joints with Various Clinical Thicknesses and Welding Pulse Energies
}

\author{
Mau-Chin LIN ${ }^{1}$, Sheng-Chieh LIN², Yu-Tsai WANG ${ }^{3}$, Suh-Woan HU', Tzu-Hsin LEE ${ }^{5}$, Li-Kai CHEN ${ }^{6}$ and Her- \\ Hsiung $\mathrm{HUANG}^{3,6}$ \\ ${ }^{1}$ Department of Dental Laboratory Technology, Central Taiwan University of Science and Technology, Taichung 406, Taiwan \\ ${ }^{2}$ Department of Dental Laboratory Technology, Shu-Zen College of Medicine and Management, Kaohsiung 821, Taiwan \\ ${ }^{3}$ Faculty of Dentistry, School of Dentistry, National Yang-Ming University, Taipei 112, Taiwan \\ ${ }^{4}$ Institute of Stomatology, Chung Shan Medical University, Taichung 402, Taiwan \\ ${ }^{5}$ School of Dentistry, Chung Shan Medical University, Taichung 402, Taiwan \\ ${ }^{6}$ Department of Dentistry, Taipei City Hospital, Taipei 115, Taiwan \\ Corresponding author, Her-Hsiung HUANG; E-mail: hhhuang@ym.edu.tw
}

Received November 10, 2006 /Accepted January 15, 2007

The purpose of this study was to evaluate the fracture resistance of Nd:YAG laser-welded cast titanium (Ti) joints with various clinical thicknesses and welding pulse energies. A four-point bending test was used to assess the effects of various specimen thicknesses $(1-3 \mathrm{~mm})$ and welding pulse energies $(11-24 \mathrm{~J})$ on the fracture resistance of $\mathrm{Nd}$ : $\mathrm{YAG}$ laser-welded Ti dental joints. Fracture resistance was evaluated in terms of the ratio of the number of fractured specimens to the number of tested specimens. As for the fracture frequencies, they were compared using the Cochran-Mantel-Haenszel test. Morphology of the fractured Ti joints was observed using a scanning electron microscope. Results showed that decreasing the specimen thickness and/or increasing the welding pulse energy, i.e., increasing the welded area percentage, resulted in an increase in the fracture resistance of the Ti joint. Where fracture occurred, the fracture site would be at the center of the weld metal.

Keywords: Fracture resistance, Thickness, Welding pulse energy

\section{INTRODUCTION}

For dental applications, titanium (Ti) has been widely used owing to its excellent biocompatibility and mechanical properties. However, practical experiences have revealed that the accuracy of the final $\mathrm{Ti}$ prosthesis may be influenced by some unavoidable errors during the fabrication process. To circumvent these unavoidable inaccuracies, clinicians try to make up for these errors by cutting and re-connecting (welding) Ti dental prostheses. Among the various welding techniques, laser welding in an argon gas environment is regularly used for the re-connection of Ti prostheses.

According to the research of Wiskott et al. ${ }^{1}$, it was found that the equiaxed grain structure of weld metal was similar to that of adjacent Ti parent metal after laser welding. In contrast, Qi et $a l .^{2)}$ reported that there were fine acicular structures in the $\mathrm{Ti}$ weld metal different from the parent metal structure after laser welding. As for tensile strength, the study of Chai and $\mathrm{Chou}^{3)}$ showed that the tensile strength of Ti weld metal was superior to the parent metal after laser welding. On the contrary, Wiskott et $\left.a l^{4}{ }^{4}\right)$ found that the tensile strength of weld metal of a laser-welded $\mathrm{Ti}$ joint was inferior to the parent metal. In addition, because of the fusion of impurities, formation of martensitic structure, or coarsening of crystal grains during the laser welding process, the Ti weld metal might become brittle ${ }^{5,6)}$.
It is evident that there is no agreement among the abovementioned studies owing to different welding parameters used, which then resulted in discrepancies of the weld metal structure and consequent changes in the mechanical properties of the weld metal. Therefore, Baba and Watanabe ${ }^{7)}$ reported that for an optimal thickness of a dental metal, it was important that suitable conditions for laser welding be selected to obtain sufficient penetration depth when welding prostheses. On this note, Liu et al. . $^{8}$ found that the penetration depth of laser-welded $\mathrm{Ti}$ was proportional to the output current. Similarly, in our recent study $^{9}$, the mechanical properties of laser-welded $\mathrm{Ti}$ joints were evaluated using a uniaxial tensile test until the tested specimens were broken, showing that elongation and tensile strength were significantly influenced by welding energy.

Based on the abovementioned literature, it is of no doubt that the mechanical properties of laser-welded $\mathrm{Ti}$ are related to welding parameters. In particular for dental applications, the fracture resistance (i.e., "broken" or "not broken") of laser-welded $\mathrm{Ti}$ prostheses is of paramount importance - although there is very limited related information in published literature. Against this backdrop of information scarcity, this study was undertaken to investigate the effects of clinical thickness and welding pulse energy on the fracture resistance of $\mathrm{Nd}$ :YAG laser-welded $\mathrm{Ti}$ joints for 
dental prostheses using four-point bending test. The hypothesis was that laser-welded $\mathrm{Ti}$ joints with different clinical thicknesses and welding pulse energies have a dissimilar fracture resistance.

\section{MATERIALS AND METHODS}

\section{Materials preparation}

A Ti casting machine (Vulcan-T, Shofu, Kyoto, Japan) was used to produce ASTM Grade 2 commercially pure Ti (Titan, Shofu, Kyoto, Japan) casting plates with a dimension of $30 \mathrm{~mm} \times 5 \mathrm{~mm}$. The various thicknesses chosen for this study were 1 , $1.5,2,2.5$, and $3 \mathrm{~mm}$ - all relevant for dental clinical applications. A MgO-based investment (Titavest CB, J. Morita, Osaka, Japan) was used with a mixture of $16 \mathrm{~mL}$ liquid and $100 \mathrm{~g}$ powder according to the manufacturer's instruction, and temperature was maintained at $500^{\circ} \mathrm{C}$ before casting.

Each cast Ti plate was evenly cut into two pieces in a direction perpendicular to the long edge of the metal plate. Both sides of the cut surface were airborne particle-abraded with $120-\mu \mathrm{m} \mathrm{Al} \mathrm{O}_{3}$ powder (White Morundum $^{\text {TM }}$ WA F120, Showa Denko K.K., Shiojiri, Japan) under $0.147 \mathrm{MPa}$ air pressure. Then, the metal plates were cleaned in alcohol in an ultrasonic bath and air-dried.

\section{Laser welding procedure}

The two pieces of cast Ti plate with uniform length were put together on a platform in a Nd:YAG laser welding machine (LaserStar, Bego, Bremen, Germany). Laser beam was aimed perpendicular to the metal plate, in an argon gas environment, with a partial pressure of $0.294 \mathrm{MPa}$. For the laser beam, a beam diameter of $0.8 \mathrm{~mm}$ and a pulse duration of $10 \mathrm{~ms}$ were chosen. Five welding voltages of 310 , $320,340,360$, and 400 volt were used for welding, which corresponded to welding pulse energies of about 11, 13, 15, 18, and 24 Joule (J), respectively,

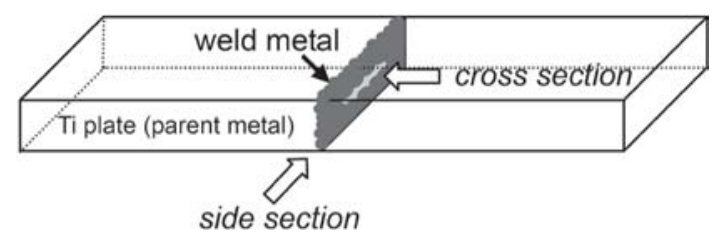

Fig. 1 Schematic diagram of Nd:YAG laser-welded cast Ti plate joint. according to manufacturer's technical specifications.

During the welding process, midpoints of the four sides of the slit between the metal plates were spot welded first to assure initial fixation and to compensate for the stress concentration that arose when welding a joint. Then, the process was followed by spot welding with a half overlap on the previous welding spot sequentially until the entire slit was encompassed. Figure 1 shows the schematic diagram of a laser-welded cast $\mathrm{Ti}$ joint. For microstructural observation, the side section of the laser-welded cast $\mathrm{Ti}$ joint (Fig. 1) was ground with \# 1500 SiC paper, and then polished with 1$\mu \mathrm{m} \mathrm{Al}_{2} \mathrm{O}_{3}$ powder. Microstructure of the weld metal was observed using a light microscope after the polished surface was acid-etched by a solution of $\mathrm{H}_{2} \mathrm{O}_{2} / \mathrm{HNO}_{3} / \mathrm{HF} / \mathrm{H}_{2} \mathrm{O}$ (3:3:1:3 in volume) for five seconds.

After completing the laser welding procedure, radiographs of the joints were obtained with an ultraspeed Kodak occlusal dental film (DF-50, Eastman Kodak Co., Rochester, USA) to verify eventual voids (resolution: few $\mu \mathrm{m}$ ). A dental X-ray machine (Oralix AC, Dentsply Italia, Milano, Italy) was set up at $65 \mathrm{kV}$ (peak), $7.5 \mathrm{~mA}$, and with a 0.9 second exposure time. All radiographs of the laserwelded cast Ti plate joints with different thicknesses and welding pulse energies presented no interval voids.

\section{Fracture resistance analysis}

To evaluate the fracture resistance of the laserwelded cast $\mathrm{Ti}$ joints, a four-point bending test was conducted on the Ti joint specimens using a universal testing machine (AG-1000 E, Shimadzu, Kyoto, Japan) with a crosshead speed of $0.5 \mathrm{~mm} / \mathrm{min}$. The four-point loading provided a uniform longitudinal tensile stress in the convex surface of the part of the specimen between the inner supports ${ }^{10)}$. Ten specimens were tested under each set of experimental

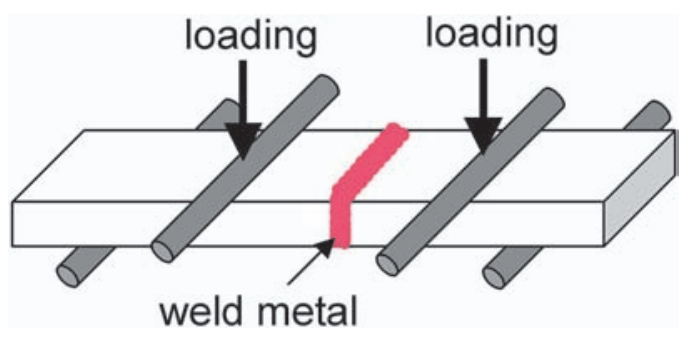

Fig. 2 Schematic diagram of four-point bending test for laser-welded cast Ti plate joint. 
conditions. Before the mechanical test, the laserwelded specimens were ultrasonically cleaned in an alcohol bath and then rinsed with distilled water.

In this study, the weld metal of the laser-welded joint was located between the inner supports and was subjected to a uniform longitudinal tensile stress during the four-point bending test. Figure 2 shows the schematic diagram of the bending test for the laser-welded cast Ti joints. During the bending test, the loading would continue until fracture occurred (i.e., the specimen broke into two pieces). On the other hand, the bending test would be terminated if the descending distance of the loading rod (Fig. 2) reached $2 \mathrm{~mm}$ (measured from the initial contact with specimen surface), even when no fracture occurred.

Under each set of experimental conditions, the number of fractured specimens was N. Therefore, ratio of the number of fractured specimens to the number of tested specimens was N/10 (as the number of tested specimens was 10). This ratio was used to assess the fracture resistance of the joints. As for the fracture morphologies of $\mathrm{Ti}$ joints after the bending test, they were observed using a scanning electron microscope (SEM) (S-3500 N, JEOL, Tokyo, Japan).

\section{Statistical analysis}

The Cochran-Mantel-Haenszel test was used to compare the fracture frequencies among the groups of different thicknesses (stratified by voltage) and different voltages (stratified by thickness). Data analysis was conducted with a statistical software (JMP version 5.1, SAS Institute, Cary, USA). Level of significance was 0.05 for all statistical tests.

\section{RESULTS}

After the welding process, the weld metal showed a uniform lamellar/acicular microstructure. This structure became coarsened with increase in welding pulse energy, regardless of joint thickness. An example illustrating the coarsening effect of welding pulse energy (13 and $18 \mathrm{~J}$ ) on weld metal microstructure (thickness: $2 \mathrm{~mm}$ ) is shown in Fig. 3.

Figure 4 shows the SEM images of the fracture surfaces of 2.5-mm-thick joints with welding pulse energies of (a) 11, (b) 15, and (c) $18 \mathrm{~J}$ after the four-point bending test. During the bending test, if failure occurred, the fracture would occur only at the center of weld metal regardless of welding pulse energy. Figure 5 shows the photograph of the side section of $\mathrm{Ti}$ joint (thickness: $2.5 \mathrm{~mm}$; welding pulse energy: $18 \mathrm{~J}$ ) after the four-point bending test, revealing that fracture occurred at the center of weld metal.

Table 1 shows the ratios of the number of fractured specimens to the number of tested specimens of laser-welded cast Ti joints with various thicknesses as a function of welding pulse energy after the four-point bending test. Results of Cochran-Mantel-Haenszel test showed that fracture frequencies were significantly different among different thicknesses (stratified by welding pulse energy, $P<0.001)$ and among different welding pulse energies (stratified by joint thickness, $P<0.001$ ).

The welded area percentages of fractured crosssections of $\mathrm{Ti}$ joints were calculated using an image analysis software (Image-Pro ${ }^{\circledR}$ Plus version 4.5.1, Media Cybernetics Inc., Silver Spring, USA) and listed in Table 2. In general, with the same joint thickness, increasing the welding pulse energy led to an increase in welded area percentage. It should be noted that for joints with a lower thickness and/or a higher welding energy, i.e., $1 \mathrm{~mm}$ thickness with all welding energies, $1.5 \mathrm{~mm}$ thickness with welding energies 噂 $15 \mathrm{~J}$, and $2.0 \mathrm{~mm}$ thickness with welding energies 18 噂 $\mathrm{J}$, the welded area percentage could not be calculated because no fractures occurred during the bending tests.

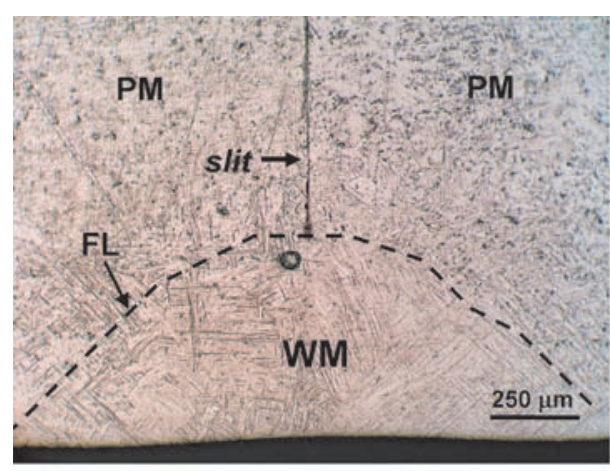

(a)

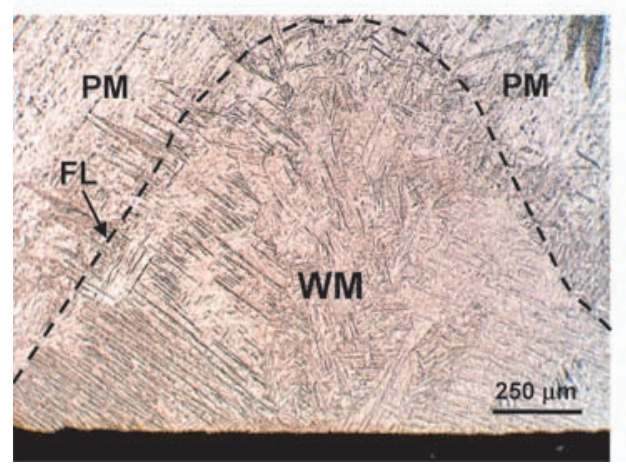

(b)

Fig. 3 Microstructure of the side section of weld metal (refer to Fig. 1) with a thickness of $2 \mathrm{~mm}$ and exhibiting the coarsened effects of welding pulse energies at $13 \mathrm{~J}$ (a) and $18 \mathrm{~J}$ (b). PM: parent metal; WM: weld metal; FL: fusion line. 

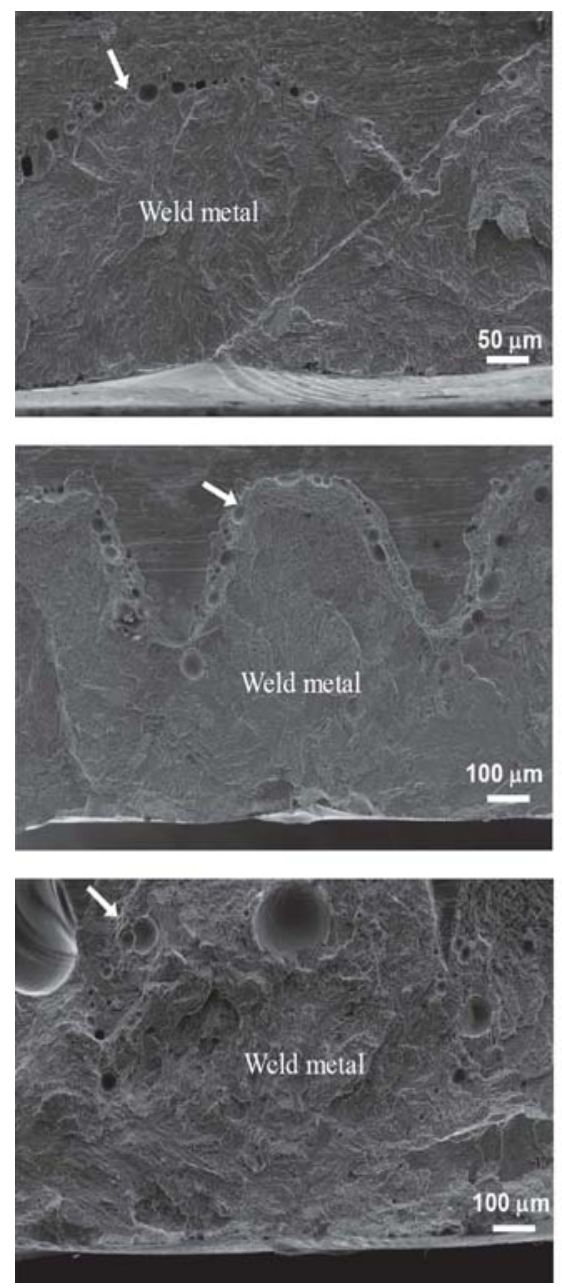

Fig. 4 SEM images of fracture surfaces of laser-welded cast $\mathrm{Ti}$ joints (thickness: $2.5 \mathrm{~mm}$ ) with welding pulse energies of (a) 11, (b) 15, and (c) $18 \mathrm{~J}$ after the four-point bending test (arrows indicated the fusion line of weld metal).

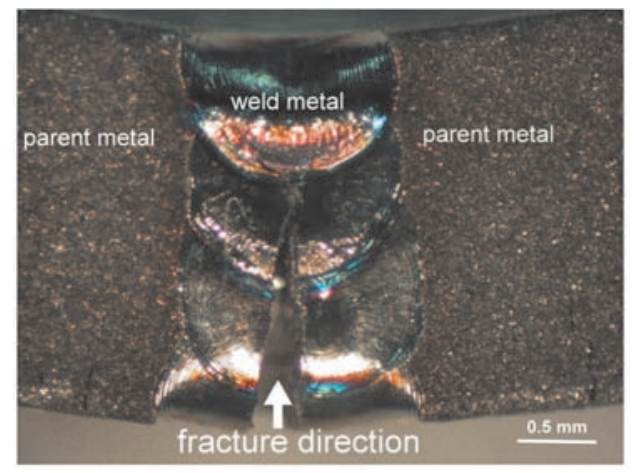

Fig. 5 Photograph of the side section of $\mathrm{Ti}$ joint (thickness $2.5 \mathrm{~mm}$; welding pulse energy $18 \mathrm{~J}$ ) after the four-point bending test, revealing that fracture occurred at the center of weld metal.
Table 1 Fracture frequencies, ratios of the number of fractured specimens to the number of tested specimens, of laser-welded cast $\mathrm{Ti}$ joints with various thicknesses as function of welding pulse energy after four-point bending test (note: number of tested specimens for each set of experimental conditions was 10)

(a)

\begin{tabular}{cccccc}
\hline & & & & & \\
Whickness, $\mathrm{mm}$ & & 1.5 & 2 & 2.5 & 3 \\
\hline 11 & & & & & \\
\hline 13 & $0 / 10$ & $8 / 10$ & $10 / 10$ & $10 / 10$ & $10 / 10$ \\
15 & $0 / 10$ & $4 / 10$ & $8 / 10$ & $10 / 10$ & $10 / 10$ \\
18 & $0 / 10$ & $0 / 10$ & $6 / 10$ & $10 / 10$ & $10 / 10$ \\
24 & $0 / 10$ & $0 / 10$ & $0 / 10$ & $8 / 10$ & $10 / 10$ \\
\hline
\end{tabular}

Table 2 Welded area percentages (\%) of fractured crosssections of Ti plate joints with various welding pulse energies and joint thicknesses. (*: No fracture occurred; standard deviations are given in parentheses.)

(c)

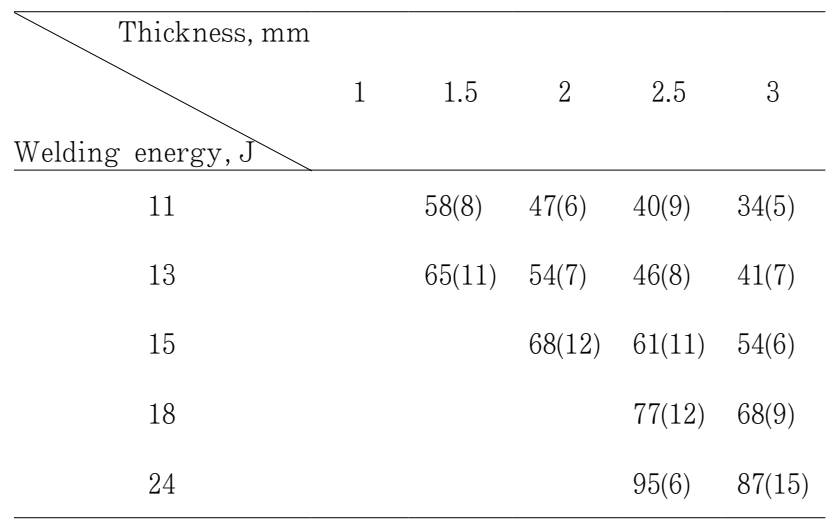

\section{DISCUSSION}

The four-point bending test results revealed that increasing the Nd:YAG laser welding pulse energy and/or decreasing the joint thickness led to an increase in the fracture resistance of cast $\mathrm{Ti}$ joints (Table 1). In other words, a joint with a higher welding pulse energy and/or a lower joint thickness was more resistant to fracture. All Ti joints with a thickness of $3 \mathrm{~mm}$ fractured during the bending test, while those with a thickness of $1.0 \mathrm{~mm}$ were resistant to fracture, regardless of the welding pulse energy. It should be noted that significant plastic deformation was observed on thinner joints $(1.0 \mathrm{~mm}$ thickness) after the bending test. 
For Ti joints with a thickness of $1.5,2$, or 2.5 $\mathrm{mm}$, weld survival rate was a combined effect of welding pulse energy and thickness of Ti joint. With a higher welding pulse energy and/or a lower joint thickness, a relatively larger welded region, i.e., higher welded area percentage, was yielded (Table 2). When the welded regions from the top and bottom of the $\mathrm{Ti}$ joint became closer (refer to cross-sectional view in Fig. 1), the welded area percentage would become higher and closer to $100 \%$. Thus, no fractures occurred during the bending test. In our previous study ${ }^{9}$, no fatigue fractures were observed for Nd:YAG laser-welded cast Ti rod joints $(3 \mathrm{~mm}$ in diameter) in an open-air environment when welding energy was higher than $15 \mathrm{~J}$. In this study, the bending test results showed that the fracture resistance of Nd:YAG laser-welded cast Ti plate joints was significantly dependent on joint thickness and welding energy (Table 1). It meant that decreasing the joint thickness and/or increasing the welding energy would lead to a lower fracture frequency of cast $\mathrm{Ti}$ plate joints.

As shown in Fig. 3, the weld metal of $\mathrm{Ti}$ joint had a uniform lamellar/acicular structure which became coarsened with increase in welding energy. Previous studies have shown that the presence of a fine acicular structure could provide the weld metal with higher cracking resistance ${ }^{1,11}$. According to the aforementioned literature ${ }^{1,11}$, it could be expected that for the same joint thickness, a $\mathrm{Ti}$ joint with a coarser lamellar/acicular structure rendered by a higher welding energy might have a lower fracture resistance (or a higher fracture frequency). However, this prospect was not in agreement with the four-point bending test results shown in Table 1.

Results of the present study showed that the fracture resistance of $\mathrm{Ti}$ plate joints depended not only on the weld metal microstructure, but also on the welded area percentage of cross-sectional surface for $\mathrm{Ti}$ plate joints. In this study, the latter factor (welded area percentage) seemed to play a more important role in the fracture resistance of $\mathrm{Ti}$ plate joints under the same welding conditions. For the same welding pulse energy or joint thickness, a higher welded area percentage led to a better fracture resistance of Ti plate joints (Tables 1 and 2). It should also be noted that the welding penetration depth of laser-welded $\mathrm{Ti}$ joints can be affected by welding pulse energy. Generally, an increase in welding pulse energy would lead to an increase in penetration depth, and thereby an increase in the welded area. Hence, welding penetration depth is indeed an important factor that affects the joint strength of laser-welded prostheses. On this note, the effect of penetration depth on joint strength warrants further investigation in future studies.

In this study, no heat-affected zones (HAZ) were observed at the interface between weld metal and parent metal for Nd:YAG laser-welded cast Ti joints. Martin et $a l .{ }^{12)}$ reported that the absence of HAZ was due to the quasi-instantaneous heating and cooling of the metal during the laser welding process. Similar results were also reported previously $y^{1,9,13)}$.

As mentioned earlier, where fracture occurred during the four-point bending test, the fracture site would be at the center of weld metal. The morphology of a fractured Ti joint with a lower welding pulse energy (Fig. 4(a)) was brittle in nature, showing a cleavage pattern. For a Ti joint with a higher welding pulse energy (Fig. 4(c)), plastic deformation was more evident on the fractured surface.

Furthermore, voids (ranging from a few tens to hundreds of $\mu \mathrm{m}$ in diameter) were observed along the weld fusion line. The weld metal with a higher welding pulse energy had larger voids. It was believed that these voids were produced during the welding process. These voids were actually induced by the incorporation of ambient gases, including argon shielding gas during the laser welding process. This was chiefly because $\mathrm{Ti}$ is highly reactive with ambient gases such as oxygen and nitrogen during the melting/solidification process at high temperature. Berg et $a l^{5}{ }^{5}$ found that the presence of large pores (a few hundreds of $\mu \mathrm{m}$ in diameter) in the weld metal appeared to be the most important factor in influencing the strength of laser-welded $\mathrm{Ti}$ joints. Similarly, in a study by Iwasaki et al. ${ }^{14)}$ on the performance of laser-welded $\mathrm{Ti}$ and dental precious alloys by mechanical testing, they arrived at the same conclusion. The authors found that porosity in the weld zone was the cause for lower welding fracture strength of dissimilar metals as compared with similar metals ${ }^{14}$. In this study, however, the four-point bending test results showed that the presence of voids (from a few tens to hundreds of $\mu \mathrm{m}$ in diameter) in the weld metal with various welding pulse energies $(11-24 \mathrm{~J})$ had no detrimental influence on the fracture resistance of cast Ti plate joints (thickness: $1-3 \mathrm{~mm}$ ).

\section{CONCLUSIONS}

Results of Cochran-Mantel-Haenszel test showed that the fracture frequencies of Nd:YAG laser-welded cast Ti joints were significantly different among different thicknesses stratified by welding energy $(P<0.001)$ and among different welding energies stratified by joint thickness $(P<0.001)$. For the same welding energy or joint thickness, the fracture resistance of Nd:YAG laser-welded cast Ti plate joints increased with increase in welded area percentage, i.e., increasing the welding energy $(11-24 \quad \mathrm{~J})$ and decreasing the clinical joint thickness $(1-3 \mathrm{~mm})$. 
The presence of voids (less than a few hundreds of $\mu \mathrm{m}$ in diameter) along the weld fusion line was not detrimental to the fracture resistance of $\mathrm{Ti}$ joints.

\section{ACKNOWLEDGEMENTS}

The authors would like to thank Taipei City Hospital (Grant No. 095XDAA00106) and Central Taiwan University of Science and Technology (Grant No. CTUST-LI-9506), Taiwan, for the partial financial support.

\section{REFERENCES}

1) Wiskott HWA, Doumas T, Scherrer SS, Susz C, Belser UC. Microstructures of brazings and welds using grade 2 commercially pure titanium. Int $\mathrm{J}$ Prosthodont 2001; 14:40-47.

2) Qi Y, Deng J, Hong Q, Zeng L. Electron beam welding, laser beam welding and gas tungsten arc welding of titanium sheet. Mater Sci Eng 2000; A280:177-181.

3) Chai T, Chou CK. Mechanical properties of laserwelded cast titanium joints under different conditions. J Prosthet Dent 1998;79:477-483.

4) Wiskott HWA, Doumas T, Scherrer SS, Belser UC. Mechanical and structural characteristics of commercially pure grade $2 \mathrm{Ti}$ welds and solder joints. J Mater Sci: Mater Med 2001; 12:719-725.

5) Berg E, Wagner WC, Davik G, Dootz ER. Mechanical properties of laser-welded cast and wrought titanium. J Prosthet Dent 1995; 74:250-257.
6) Yung WKC, Ralph B, Lee WB, Fenn R. An investigation into welding parameters affecting the tensile properties of titanium welds. $\mathrm{J}$ Mater Process Technol 1997; 63:759-764.

7) Baba N. Watanabe I. Penetration depth into dental casting alloys by Nd:YAG laser. J Biomed Mater Res B: Appl Biomater 2005; 72:64-68.

8) Liu J, Watanabe I, Yoshida K, Atsuta M. Joint strength of laser-welded titanium. Dent Mater 2002; 18:143-148.

9) Huang $\mathrm{HH}$, Lin CC, Lin MC, Lin SC, Hsu CC, Chen FL, Lee SY, Hung CC. Effects of welding pulse energy and fluoride ion on the cracking susceptibility and fatigue behavior of Nd:YAG laser-welded cast titanium joints. Dent Mater J 2006; 25:632-640.

10) Sedriks AJ. Making and using bend-beam specimens. In: Corrosion testing made easy (Volume 1): stress corrosion cracking test methods, 9th ed, National Association of Corrosion Engineers, Houston, 1990, pp.19-24.

11) Wiskott HW, Macheret F, Bussy F, Belser UC. Mechanical and elemental characterization of solder joints and welds using a gold-palladium alloy. J Prosthet Dent 1997; 77:607-616.

12) Martin G, Albright C, Jones T. An evaluation of $\mathrm{CO}_{2}$ laser beam welding on Ti-3Al-Nb alloy. Welding Res Suppl 1995; 74:77-82.

13) Neo TK, Chai J, Gilbert JL, Wozniak WT, Engelman MJ. Mechanical properties of titanium connectors. Int J Prosthodont 1996; 9:379-393.

14) Iwasaki K, Ohkawa S, Uo M, Akasaka T, Watari F. Laser welding of titanium and dental precious alloys. Mater Trans 2004; 45:1140-1146. 